\title{
La revista de los 100 años
}

\author{
Jorge Luis Molinas
}

Decano de la Facultad de Ciencias Médicas

Bienvenidos a la edición 2020 de la Revista de la Facultad de Ciencias Médicas (FCM) de la Universidad Nacional de Rosario. La misma está destinada a la difusión de temas científicos vinculados con la investigación básica, clínica, epidemiológica y social que hacen al proceso de salud y enfermedad. Igualmente apunta a ser un instrumento para la divulgación de artículos relacionados con la historia de la Medicina en general y en particular de la FCM. Se trata de un significativo y valioso esfuerzo colectivo de autores, evaluadores y personal a cargo de las secretarías de Ciencia Tecnología e Innovación y de Prensa.

El año 2020 dejará un registro difícil de borrar en la memoria colectiva. La pandemia más importante del siglo (COVID19) en una facultad cumpliendo su primera centuria trabajando sin tregua.

\section{La ciencia en tiempos de pandemia}

La aceleración en el desarrollo tecnológico durante el último siglo tuvo que ver en gran medida con las mejoras en la forma de hacer, practicar y divulgar la ciencia, la cual ha impregnado todos los ambientes académicos.

La FCM también persigue este mandato, con sólidos equipos de investigación, que a pesar de las limitaciones en cuanto a recursos, esfuerzo y empeño aplicados, han permitido llevar adelante investigaciones en temas prioritarios para el sector salud en un país subdesarrollado (Chagas, tuberculosis, cáncer, enfermedades crónicas no transmisibles, aspectos genéticos y sociales de diversas patologías, entre otros).

El comienzo de la pandemia fue signado por un aparente retroceso, necesario por ser la única herramienta disponible: aislamiento, distanciamiento y limitación de la circulación de personas.

Lainiciativa científica fue rápidamenteadaptando el sistema paragenerar la másgrandevirtualidad académica y técnica que se haya visto en la historia de la humanidad. A pesar de la "cuarentena", los científicos se acercaron más que nunca en encuentros virtuales de diferentes disciplinas y la oferta de formación fue más grande que lo habitual.

El mundo comenzó una carrera orientada a desarrollar la vacuna anti COVID19, la cual desembocó en desarrollos innovadores que habrían tenido que esperar años en otros momentos de la historia de la humanidad. El final de este recorrido, que el ser humano celebrará victorioso, lleva signado el manejo del poder, que como en otros adelantos científicos es susceptible de ser desigualmente empleado.

Como hecho antagónico hemos sido testigos del costo político asumido por algunos líderes mundiales al ignorar el método científico en la construcción de conocimiento. También hemos observado con asombro la proclamación de medicamentos "milagrosos" introducidos bajo preceptos intuitivos, completamente alejados de la evidencia clínico—epidemiológica que los sustenten.

\section{Ciencia y sociedad en pandemia}

La "cuarentena" como método inicial tendiente a limitar la extensión de la pandemia y ganar tiempo para preparar al sistema de salud fue una intervención social razonable frente al desborde observado en países del primer mundo. En paralelo al éxito del método para bajar el número de casos, el aislamiento paralizó grandes sectores de la economía, sobre todo los más pobres, mientras otros, como los financieros o los dedicados a la exportación o los gigantes de la salud privada no frenaron su crecimiento. 
La pobreza estructural de la Argentina hizo muy difícil aplicar la "cuarentena" en forma simétrica y absoluta, sobre todo porque las medidas económicas tomadas no alcanzaron para paliar el hambre, el desempleo y el hacinamiento, entre otros.

La ciudadanía tuvo actos de enorme arrojo, en medio del aislamiento, con sus organizaciones sociales e instituciones (como nuestra facultad), asistiendo al pueblo en sus necesidades y en cierta medida contribuyendo a que el deteriorado sistema de salud no colapsara en general. Aún así no se pudo evitar el crecimiento de los casos, y una gran cantidad de fallecimientos por millón de habitantes, entre las más grandes del mundo. Paralelamente se debilitaron los sistemas de prevención y atención para los demás problemas de salud poblacional, sumando más decesos a la lista.

Al unísono, el personal de salud, un sector social crónica e históricamente castigado, brindo su conocimiento y capacidad al máximo y pagó con vidas y heridas que difícilmente puedan cerrar.

Este sistema de aislamiento fue flexibilizando conforme la economía y la ciudadanía lo demandaba, aprovechando la disminución del número de casos en algunos momentos y sumando un elemento clave que en la segunda mitad del año asomó prometedora de la mano de grandes corporaciones y países del primer mundo: la vacuna contra la COVID19.

La vacuna se posiciona hoy como la herramienta fundamental en la lucha contra la pandemia. Basta mirar la historia de la medicina desde Edward Jenner hasta la fecha para entender la importancia de la inmunización activa. Sin embargo, sectores minoritarios de la sociedad, por oportunismo político o descreimiento de la ciencia, quisieron desestabilizar esta estrategia.

Por otro lado, la vacuna contra el coronavirus es un negocio cautivo de más de 7.000 millones de usuarios y las empresas farmacéuticas no trabajan como voluntariados sociales y en algunos casos se han visto involucrados en problemáticas sanitarias que serán recordadas por la historia de la medicina y del derecho (talidomida, terapia hormonal de reemplazo, opiáceos, entre otros).

También la vacuna, como avance científico, muestra el lado más crudo de la desigualdad social. La distribución no es equitativa mundial ni regionalmente y se usa en disputas políticas. Países como la Argentina producen los principios activos de las vacunas que luego viajan a otro país para envasarse, abandonando una región que clama por ellas.

\section{La FCM en tiempos de COVID19}

Mientras se escribe esta editorial, cientos de estudiantes de nuestra facultad se encuentran colaborando voluntariamente día tras día con las autoridades sanitarias en la campaña de vacunación más importante de los últimos 100 años. Lo mismo ocurría al principio de la pandemia con la vacunación antigripal en la puerta de la institución.

Con idéntico grado de compromiso por ayudar al pueblo que la sostiene, primero voluntariamente y luego como parte de su formación práctica, los estudiantes realizaron más de 70.000 llamados a enfermos en el Centro de Seguimiento COVID19 de nuestra facultad en Rosario y localidades vecinas. Esta estrategia surgió y se realizó en la FCM con la supervisión de las autoridades sanitarias.

En el mismo sentido, se prestaron instalaciones docentes a los hospitales Centenario y Eva Perón, se hicieron donaciones, actividades barriales y asesoramientos de gran utilidad para nuestra comunidad.

Hacia adentro hubo que garantizar el cuidado de la salud con medidas específicas para cada grupo particular de docentes, estudiantes y no docentes con el principal objetivo de sostener los procesos de aprendizaje e investigación y con ello, la graduación de nuestros estudiantes, para contribuir al sistema de salud con nuevos profesionales.

En un gran esfuerzo de todos los sectores de la FCM se sostuvieron más de 500 comisiones virtuales, más de 300 seminarios en vivo y grabados en video, 32.558 presentes a exámenes virtuales en todos los turnos en las tres carreras (Licenciaturas en Enfermería, en Fonoaudiología y Medicina) y se pudo entregar más de 700 diplomas de títulos de grado, posgrado e intermedios. A principios del mes de julio se realizaba el primer examen presencial del área salud a nivel país que agregaba 175 médicos más al sistema de salud, situación que se encontraba bloqueada hasta ese momento.

Los investigadores, fieles a su esfuerzo aún en las condiciones más adversas, continuaron su labor resultando en más de 100 presentaciones a congresos, publicaciones en revistas indexadas, disertaciones, premios de investigación y reconocimientos personales.

Tan destacable fue la labor de los actores de la FCM que aún en etapas de gran incertidumbre más de 1000 docentes y estudiantes-ayudantes realizaron los cursos del Área de Formación Docente, y más de 600 personas participaron en una o más actividades propuestas para la formación y sensibilización en temática de género. Finalmente, luego de muchos meses alejados de nuestra 
querida Casa de Estudios, estudiantes y docentes volvieron a las clases presenciales, en grupos reducidos y distanciados, para realizar las prácticas pospuestas.

\section{El siglo de la FCM}

La FCM nació en conmemoración del primer Centenario de la Independencia Nacional, y con el objetivo de erigir un Hospital Escuela que dé soluciones y respuestas a las demandas de una población que comenzaba a crecer rápidamente. Hija de la Reforma Universitaria de 1918, bajo la Presidencia del Dr. Hipólito Yrigoyen, el 9 de Abril de 1920 se crea como institución de la Universidad Nacional del Litoral. En 1968 pasa a formar parte de la Universidad Nacional de Rosario.

En un siglo se vivieron todo tipo de sensaciones, aires de renovación, tiempos de censura y persecución y también de movilización y encuentro. Nuestra Centenaria Institución ha sido testigo de guerras, dictaduras, revoluciones, movilizaciones, cambios políticos, avances tecnológicos, cambio de siglo y de milenio.

Del fervor estudiantil y la pasión por la educación, nacen brillantes y comprometidos profesionales de la salud que hoy la prestigian en nuestro país y el mundo. La cercanía desde su génesis al Hospital Centenario, la posterior incorporación de unidades docentes asistenciales en otros efectores (Hospitales Eva Perón, Provincial, Intendente Carrasco, Clemente Álvarez, Victor J. Vilela y Roque Sáenz Peña) así como su integración al resto del Sistema de Salud y la comunidad, han generado profesionales y políticas que marcaron fuertemente a la Salud Pública de Rosario.

En una región que se encuentra en el centro de la zona exportadora de granos más concentrada del mundo, por donde sale la materia prima y los capitales de nuestro país dejando dividendos para pocos y miseria para muchos, la gratuidad, el ingreso irrestricto y el sueño de garantizar masividad y calidad, son consecuencia de profundas luchas de estudiantes y trabajadores, que posibilitan disponer de un talento humano que asiste al pueblo en las más diversas circunstancias, intentando garantizar la igualdad de oportunidades a una sociedad con profundas desigualdades.

La FCM tiene un lugar ganado en el corazón de la sociedad, trabajando incansablemente para ser cada vez más participativa, democrática y abierta. Debemos promover como facultad graduados con ideas firmes, claras e independientes del dogma superior, que no se subordinen, aunque eso signifique no ser apreciado por los estratos del poder.

La educación es demasiado valiosa como para que sea solo un privilegio de quienes puedan pagarla. A 100 años de su creación, la FCM sigue levantando las banderas de la salud y educación pública y eso se plasma en esta revista.

Esta edición es la muestra del esfuerzo científico de una institución que pretende que estemos juntos para cuidar la salud, terminar con las injusticias que la deterioran y continuar el trabajo llevado adelante por varias generaciones para seguir garantizando el derecho a la Educación Pública.

Estaediciónestádedicadaalosprofesionalesdelasaluddenuestraregiónqueotorgaronsuvida luchando contra la pandemia. 